\title{
Innovative solutions in monitoring systems in flood protection
}

\author{
Klaudia Sekuła ${ }^{1, *}$, Marzena Połeć ${ }^{1}$, and Aleksandra Borecka ${ }^{1}$ \\ ${ }^{1}$ AGH University of Science and Technology, Department of Hydrogeology and Geology \\ Engineering, Krakow, Poland
}

\begin{abstract}
The article presents the possibilities of ISMOP - IT System of Levee Monitoring. This system is able to collecting data from the reference and experimental control and measurement network. The experimental levee is build in a 1:1 scale and located in the village of Czernichow, near Cracow. The innovation is the utilization of a series of sensors monitoring the changes in the body of levee. It can be done by comparing the results of numerical simulations with results from installed two groups of sensors: reference sensors and experimental sensors. The reference control and measurement sensors create network based on pore pressure and temperature sensors. Additionally, it contains the fiber-optic technology. The second network include design experimental sensors, constructed for the development of solutions that can be used in existing flood embankments. The results are important to create the comprehensive and inexpensive monitoring system, which could be helpful for state authorities and local governments in flood protection.
\end{abstract}

Keywords: ISMOP, flood protection, levees, levee monitoring system

\section{Introduction}

Climate change and increasing human influence in the natural ecosystems of rivers pose a greater risk to flooding in areas near the riverbeds. This causes the public a greater interest in river embankments, their technical state and the threats they carry.

ISMOP - IT System of Levee Monitoring, which was created in cooperation with AGH University of Science and Technology and companies: SWECO Hydroprojekt Kraków and Sp. z o.o., Neosentio, has the task of supporting local authorities in flood protection and also for the development of an early warning network. The result of project will be the separation of recommended sensors and controls, which can be implemented in flood protection systems. Based on sensor data and analysis, the system will send a warning signal to the crisis management panel. Similar projects were carried out in Denmark, the Netherlands [1-2] and France [3], but the ISMOP project is unique in scale. The 1:1 experimental levee was built for this purpose, and an extensive network of sensors not

*Corresponding author: klaudia.sekula@agh.edu.pl 
previously used jointly in the single hydrotechnical object was installed in its body. The data provided in this way is compared with the results of numerical simulations. This is an innovative project that combines many areas of science to achieve a common goal of creating a reliable flood warning system by developing methods and tools for forecasting floodplains especially during floods [4-6].

\section{Characteristics of the object}

The experimental flood embankment is located in Czernichów, about $30 \mathrm{~km}$ west of Cracow. It consists of two parallel levee segments in the shape of an ellipse. It was built on a scale $1: 1$, with a length of $200 \mathrm{~m}$ and a width of $53 \mathrm{~m}$. It is capable of holding $28500 \mathrm{~m}^{3}$ of water, the height of the levee is $4,5 \mathrm{~m}$ and the maximum height of the flood wave is $4,0 \mathrm{~m}$. Levee was constructed of soils characterized by variable filter coefficients in the range from $10^{-5} \mathrm{~m} / \mathrm{s}$ to $10^{-8} \mathrm{~m} / \mathrm{s}$ (Figure 1.) with a built-in control and measurement networks. 


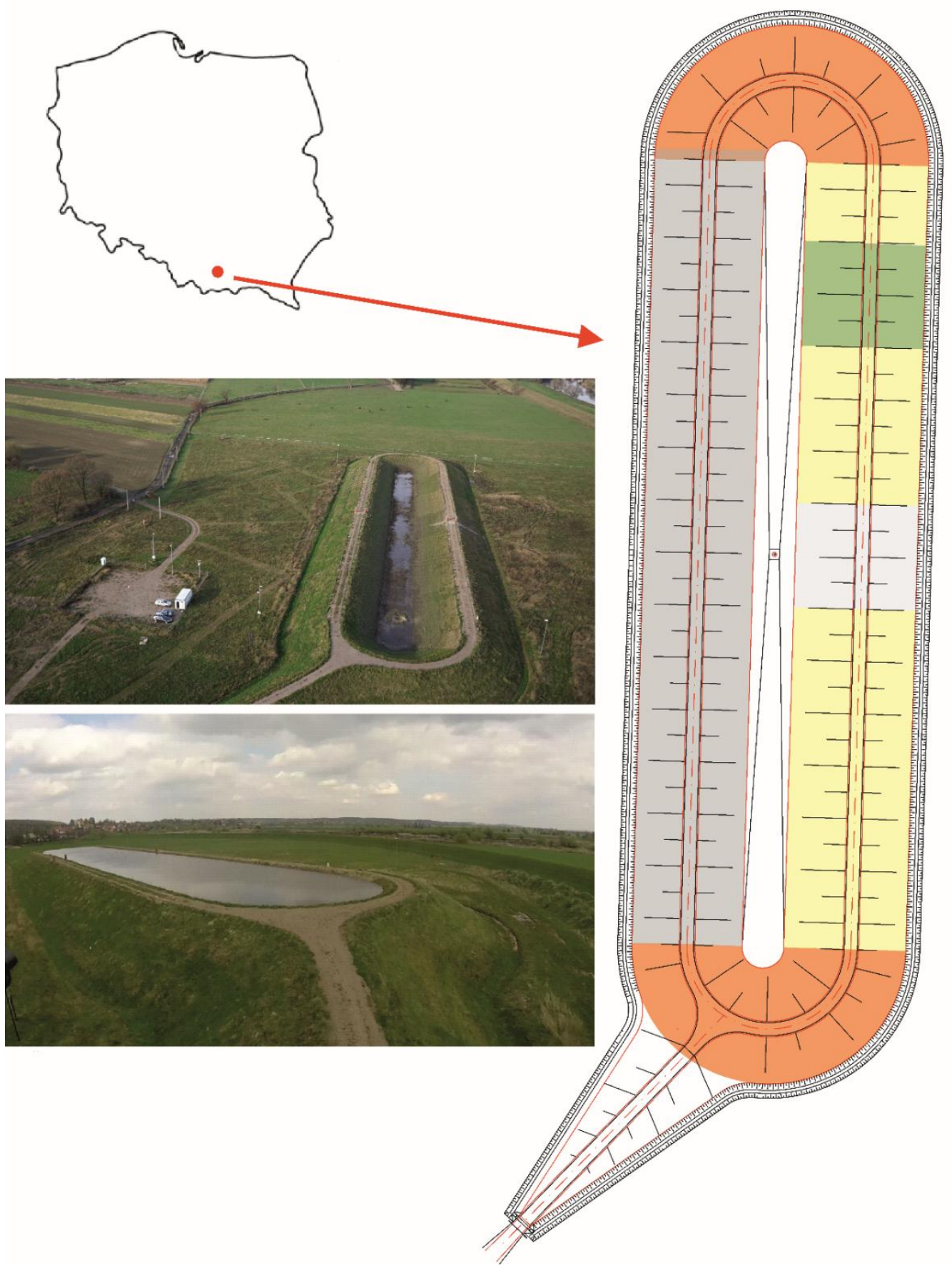

Fig.1.The diagram of the levee with the map specifying the location on in the province/ Europe (photo by Sonia Bazan). 
The control and measurement system consists of two elements: the control and measurement equipment built into the experimental levee and the automatic measurement system that collects, processes and visualizes the data obtained from the experimental measurements.

The control and measurement equipment includes the reference network and experimental network. The reference control and measurement network based on specific historically proven technologies and consists of 35 sensors for spot measurement of pore pressure and temperature, and 6 sensor for measurement ground pressure located in measuring sections. There is also a fiber optic sensor cable for the linear measuring of the temperature gradient, inbuilt on two levels of the downstream slope (Figure 2.). Sensors for pore pressure, temperature and ground pressure measurement are located in three sections of levee: southern, central and northern. The experimental control and measurement network based on the alternative technological solutions and on the distributed measurement using the MESH topology proposed by NeoSentio Sp. z o.o. There are about 1000 sensors of the experimental control and measurement network (Figure 3.) that measure pore pressure and temperature [7].

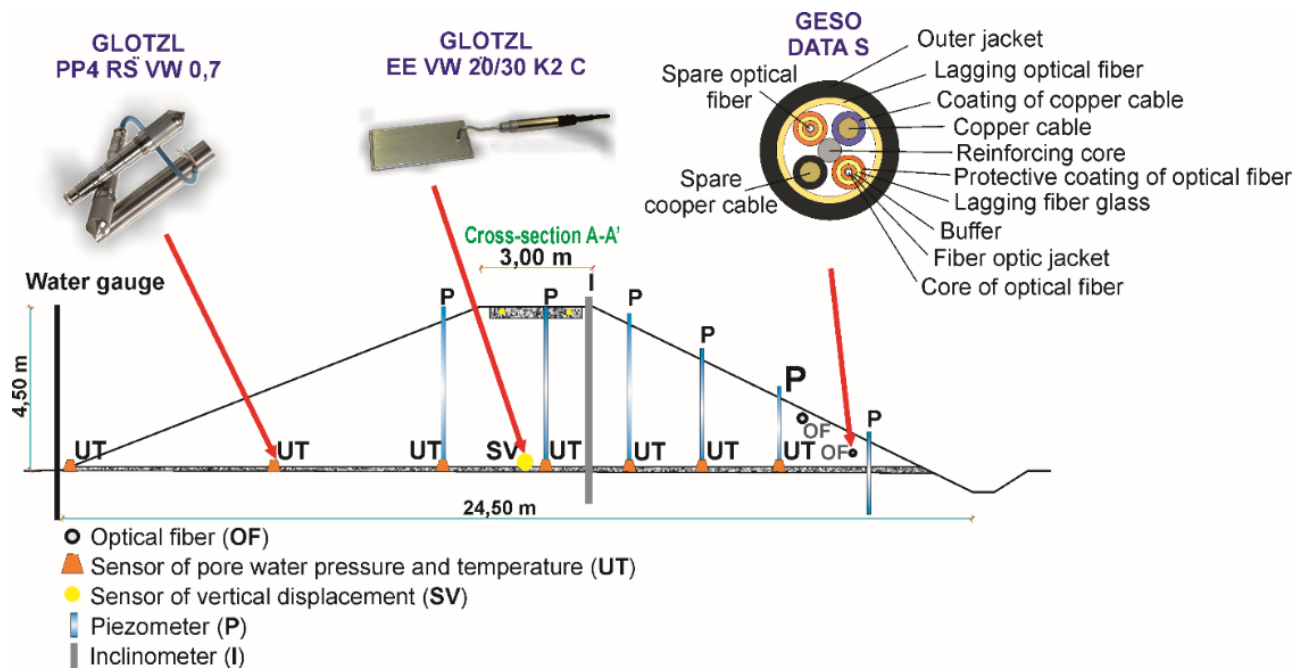

Fig.2.Location and types of sensors placed in reference control and measurement network of levee[8].

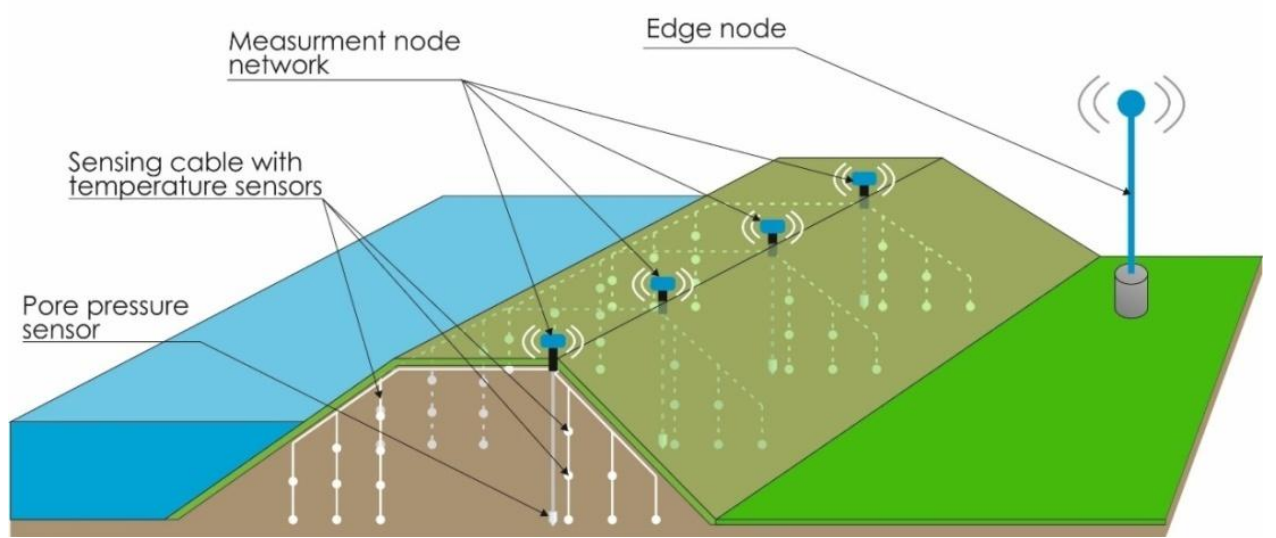

Fig.3.Schematic illustration of the idea of experimental measuring network - a matrix of sensors, a number of measuring nodes and an external base station from the edge node[7]. 
Mechanical and physical parameters measured by sensors are recorded and analyzed by Monitoring \& Modeling Center. It is system which is based on the incoming sensor data and numerical models will perform during the current risk assessment. In addition, the system is enable data visualization on synoptic maps (meteorological data), and models of the monitored sections of the shaft (data from telemetric network) and view historical data. Based on the analysis of the measured parameters will be triggered alarm, providing the occurrence of a crisis situation [9]. Exemplary screens from Monitoring \& Modeling Center are presented on Figure 4.

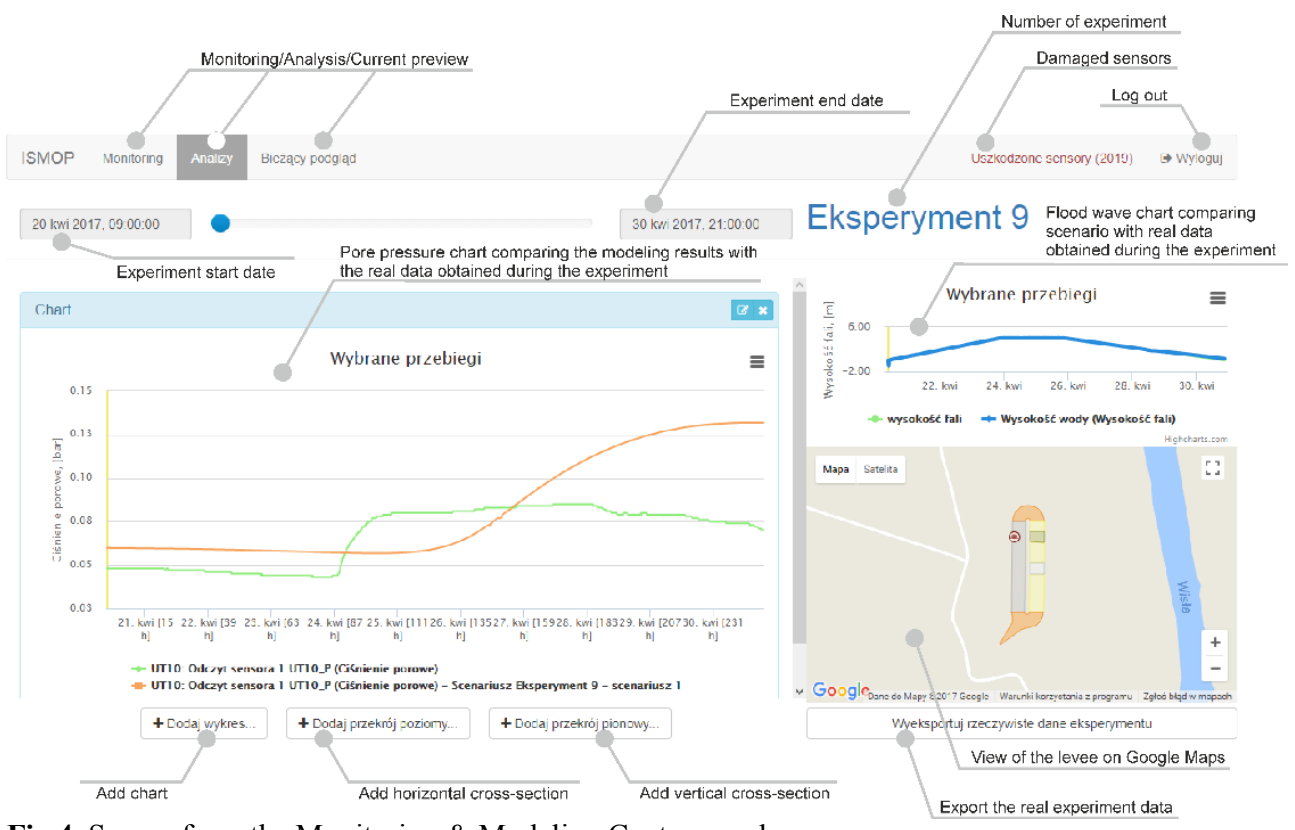

Fig.4. Screen from the Monitoring \& Modeling Center panel.

What is one of the most important aspect, the experimental levee in Czernichów reflects the majority of flood embankments in Poland. It has been designed with a number of technical solutions which have a task to imitate the real problems occurring in the existing hydrotechnical contractions. They are, for example, horizontal drainage (north-west section) designed to imitate animal burrows or a sand lens (south-west section) designed to imitate frequent interlaces of good permeability materials encountered in older embankments. The experimental levee was also covered with vegetation, which was supposed to stabilize the slopes and reflect the conditions that prevail in such hydrotechnical constructions in the country.

In addition, it is carried out the monitoring of levee surface using geodetic network to register displacements and deformations of levees based on classical methods (total stations, possibly GPS). The monitoring also using measurements provided by ground radar interferometer (IBIS-L). During the experiments were also used infrared camera FLIR T620. On the outer parts of the levee there is conducted geophysical measurements with the use of geoelectrical tomography [4]. 


\section{Experiments}

The experiments consist in simulating the static flood wave using the pump system located in the Vistula River, which filling the tank of levee to the appointed water level. Up to this article, 10 experiments were conducted (as of 10.06.2017). Each of the experiments was characterized by an individual flood scenario, namely the time of arrival of the flood wave, its height and duration (filling the tank phase, plateau phase and emptying the tank phase). Automated system for conducting experiments on the experimental levee allows for manual and automatic (remote) control. Based on the flood scenarios, the flood embankment is filled and the sensor data is monitored and made available on a special panel of Monitoring and Modelling Center with access for the researchers involved in the project (Figure 4). In next step these data are analyzed by comparing the results obtained with the numerical modeling effect. An important aspect of the functioning of the panel is the archiving of data from previous experiments. Obtained data are used to create further simulations and are helpful in forecasting the effects of floods.

\section{Preliminary results}

Measurement experiments are still during implementation and detailed analysis of the results obtained. The preliminary results of these were presented in publications Chuchro et al. [6], Borecka et al. [10]. One of their most important issues was enabled the control of the operation of the automated pump system, and the identification of factors that could interfere with measurements, as well as to determine the correctness of the experiment, and to prepare instructions for subsequent simulation experiments.

In each experiment, temperature, pore pressure and deformation were measured. Data obtained from sensors measuring pore pressure and temperature allow to plot changes in the water table level over time. In next step it was able to determine how deep the water infiltrate into the levees body and allows the earlier detection of damage that it can cause.

The first of the experiments allowed only for observation of levee behavior. As the duration of the flood wavelength in next experiments, changes of parameters values made it possible to define a part of the levee that has leaked, what was confirmed in fact.

\section{Summary}

Collected data from the sensors will become the basis for analyzing the real dangers of leaks or loss of slopes stability in the levees. Thanks to these data, it will be possible to identify areas that are particularly susceptible to damage and rapid response of emergency services and their modernization after the flood wave has subsided. Ultimately, this system is intended to assist local governments and emergency situations to send an alarm if anomalous readings occur or the limit values are exceeded. Designed from the ground monitoring system for flood embankments is applied in the centers of crisis management, which allows for faster and more effective response, eg. the evacuation of the population from the area exposed to flooding as a result of floodbank failures. Simulations that can be made based on the data of the experiments show the changes that occur in the embankments as a result of water soaking, which will allow for predictions of flood effects in future based on real time analyzes. This is an innovative approach to the issue of flood protection. In Europe, similar projects were created, but they were not carried out on such a large scale and with such an extensive network of measurement. 
Acknowledgments. The project is financed under grant No. PBS1/ B9/18/2013 awarded by the National Centre for Research and Development within the framework of the Applied Research Programme.

\section{References}

1. J.R. Courivaud, P. Pinettes, C. Guidoux, J.J. Fry, Y.L. Beck, Fiber Optic based monitoring of levees and embankment dams, 21st Century Dam Design - Advances and adaptations, 31st Annual USSD Conference, 11-15 April, San Diego, 1560-1577 (2011)

2. M.A. Van, C. Zwanenburg, A.R. Koelewijn, H. Van Lottum, Evaluation on full scale levee stability tests at booneschans and coresspondig Centrifuge Test, 17th ICSMGE, 5-9 October 2009, Alexandria, Egypt, 2048-2051 (2009)

3. O. Artieres, Y.L. Beck, A.A. Khan, P.Cunat, J.J. Fry, J.R. Courivaud, C. Guidoux, P. Pinettes, Assessment of dams and dikes behavior with a fibre optics based monitoring solution, 2nd Conference on dam rehabilitation and Maintenance, 23-25 November, Taylor \& Francis Group, London, 79-86 (2010)

4. J. Stanisz, K. Korzec, A. Borecka, Geol., Geophys. and Envi. Protec., 41(1), 137-139 (2015)

5. A. Borecka, J. Stanisz, K. Korzec, A. Leśniak, Smart levee in Poland, FLOODrisk 2016, 258 (2016)

6. M. Chuchro, A. Franczyk, B. Bukowska-Belniak, A. Leśniak, Flood risk reducing using Computer System for Monitoring River Embankment, Technologie informatyczne w ochronie i kształtowaniu środowiska: I konferencja naukowotechniczna: 17 January 2017, Warszawa (in Polish) (2017)

7. K. Sekuła, A. Borecka, D. Kessler, P. Majerski, Comp. Sci., 18(4), 357-284 (2017)

8. A. Borecka, K. Korzec, J. Stanisz, Full-scale monitoring system of levees, CGW Workshop'16: proc., 49-50 (2016)

9. J. Stanisz, A. Borecka, A. Leśniak, K. Zieliński, Prz. Geol., 62, 699-703 (in Polish) (2014)

10. A. Borecka, K. Korzec, B. Bukowska-Belniak, M. Dwornik, A. Leśniak, Smart Levee in Poland - preliminary results of experiment, Problemy hydrotechniki: XI konferencja naukowo-techniczna, 10-12 maja 2017, ŚwieradówZdrój, Poland (2017) 